\title{
Investment and Inequality in Pakistan's Education Sector
}

\author{
K hw aja Sarmad, Fazal Husain and G. M. Z ahid*
}

In this paper we present arguments for increasing expenditure on the education sector. We show that there exist large inequalities in the distribution of education services across regions and across genders so that ensuring equal opportunity for all in education, either for normative or economic reasons, will require large additional investments in this sector. We also present evidence which shows that while the rate of return to education in the country may not be high it has been increasing over time, so that higher expenditure on the education sector is also economically justifiable. Enrollments at all levels have been increasing over time, along with household and institutional expenditure on the education sector, which suggests a greater willingness to invest in education. If the productivity of education is low then it would be natural to expect a decline over time in the willingness of the people and the government to bear the costs of education. But first, we examine the evidence about the increasing unemployment of educated labour and show that this does not mean that there is an economic surplus of education in the country, nor that the education sector is overextended, but that it can be explained by 'search time'.

\section{EDUCATED UNEMPLOYED}

The Labour Force Survey for 1986-87 shows an increase in the proportion of unemployed educated labour in the total from less than 43 percent in $1982-83$ to almost 50 percent in $1986-87$. During the same period, the proportion of highly educated unemployed labour i.e. graduates and those with more than graduate training, has more than doubled, from 1.66 percent of the total unemployed, to 3.86 percent. The total number of unemployed workers with ten or more years of education is now 181 thousand, while the number of unemployed workers with graduate or higher degrees is almost 35 thousand or almost twice as many as in 1984-85.

*The authors are Chief of Research, Staff Economist and Staff Demographer, respectively at the Pakistan Institute of Development Economics, Islamabad. 
This is clearly an alarming situation. It leads to the suggestion that there may be an economic surplus of education in the country, where only 30 percent of the population is literate, implying that the education sector in the country is overextended. But the little evidence that is available about the educated unemployed suggests that this is unjustified. The problem of educated unemployment arises not because the unemployed are educated but because of search time. A large majority of the educated unemployed are young who eventually find employment, see Khan and Ali (1986). An extended family system enables the educated unemployed to search for suitable jobs for a time period which is short enough to keep the return to investment in education positive.

\section{INVESTMENT IN EDUCATION}

No estimate of investment in education is available for Pakistan. The reported public expenditure on the education sector does not include the rental value of fixed assets and the Household Income and Expenditure Surveys have no information about the income foregone by students. In the absence of such information we use expenditure on education as a proxy for investment. Table 1 reports the institutional and household expenditure on education.

Table 1

Investment in Education in Pakistan

(Million Rupees)

\begin{tabular}{lccccc}
\hline \multirow{2}{*}{ Years } & $\begin{array}{c}\text { Household } \\
\text { Expenditure Expenditure }\end{array}$ & $\begin{array}{c}\text { Institional } \\
\text { centage of } \\
\text { National } \\
\text { Income }\end{array}$ & $\begin{array}{c}\text { Social } \\
\text { Expenditure }\end{array}$ & $\begin{array}{c}5 \text { As Per- } \\
\text { centage of } \\
\text { National } \\
\text { Y. }\end{array}$ \\
\hline \multicolumn{1}{c}{1} & 2 & 3 & 4 & 5 & 6 \\
\hline $1968-69$ & 345.9 & 553.0 & 1.46 & 898.9 & 2.37 \\
$1969-70$ & 429.0 & 578.7 & 1.33 & 1007.7 & 2.32 \\
$1970-71$ & 452.7 & 789.9 & 1.72 & 1242.6 & 2.71 \\
$1971-72$ & 525.0 & 796.8 & 1.60 & 4988.3 & 2.65 \\
1979 & 1657.6 & 4153.5 & 1.81 & 5811.1 & 2.54 \\
$1984-85$ & 3557.9 & 8893.4 & 1.90 & 12451.3 & 2.65 \\
\hline
\end{tabular}

Source: Calculated from Government of Pakistan (1984-85) and (1987).
The table shows that while the absolute amount of social expenditure on the education sector has been increasing over time its growth during the decades of the Seventies has been less than the growth of national income. In consequence, educational expenditure, as a percentage of GNP, has declined during the Seventies from 2.71 percent in 1970-71 to 2.54 in 1979. Though the total social expenditure on education has increased during the Eighties to 2.65 percent of GNP it compares poorly with the expenditure of 3.4 percent of GNP in 1985 by the public sector alone for the lower middle-income countries as a whole. However, since the Seventies the increasing share in national income of institutional expenditure on education reflects an increasing willingness of the government to bear the costs of education.

Table 2 shows that the share of private expenditure on education in the total private expenditure, which had reached a high point of 1.27 percent in 1972, declined in subsequent years to reach 0.86 percent of total private expenditure in 1979. In the rural areas the decline in the expenditure on education during the period 1972 to 1979 was significant as the share of education in total expenditure declined from 0.77 percent to 0.48 percent respectively. The behaviour of private expenditure on education during the decade of the Seventies seems to conform to the finding about the low rates of return to education as there is a strong correlation between the decline in household expenditure on education and the low rate of return to education. ${ }^{1}$ Moreover, this was also a period of large-scale out-migration of labour and it can be argued that because of labour shortage, particularly in the rural areas, the opportunity cost of education must have been high.

In the absence of any evidence about the rate of return on investment in education in recent years the above suggests that since 1979 there may have been an increase in the expected return from investment in education. It is possible that the increase in the proportion of total household expenditure allocated to education, during the period 1979 to $1984-85$, from 0.86 percent to 0.92 respectively, was accompanied by an increase in the expectations regarding the return to investment in education (i.e. only if the cost of education did not increase relative to household expenditure)

'There are few estimates of the private rate of return to education in Pakistan. Among those that are available the tendency is for the rate of return to be low for all levels of education [see e.g. Haque (1977) and Guisinger (1984)] except in the case of Hamdani (1977). The most recent estimates for the rates of return to education in Pakistan are for the year 1979 [Khan and Irfan (1985)], which are also low but show increasing private returns to education. If individual externalities to educational investment are taken into account they would increase the returns to education. However, the operation of the $\alpha$-factor would serve to depress the rates of return to education although in the case of Pakistan it would not be far fetched to assume that the effect of 'innate ability' on earnings is only minimal because of low lateral mobility. On the other hand, the influence of parental status on gaining access and achieving success in the labour market is significant [see e.g. Khan and Irfan (1985)]. 
Table 2

Private Expenditure on Education (as a Percentage of Total Household Expenditure)

\begin{tabular}{cccc}
\hline Years & $1971-72$ & 1979 & $1984-85$ \\
\hline Total & 1.27 & 0.86 & 0.92 \\
Urban & 2.26 & 1.27 & 1.39 \\
Rural & 0.77 & 0.48 & 0.69
\end{tabular}

Source: Calculated from Government of Pakistan (Various Issues).

\section{INEQUALITIES IN ENROLLMENTS}

The enrollment rates in primary and secondary education in Pakistan are low. The five year average rates for the years 1980-81 - 1984-85 are only 44.3 percent and 18.5 percent, for primary and secondary education, respectively. But they represent a significant improvement since the early Fifties, when the enrollment rates were 31.1 percent and 9.6 percent, for primary and secondary education, respectively. However, the inter-regional and inter-gender inequalities in the enrollment rates continue to persist even though there has been a marked improvement over time in female enrollments both at the primary and secondary levels.

In the early Fifties females were enrolled in primary education, on an average, 4.8 times less frequently than males, whose average enrollment rate did not exceed half the population of the relevant age group. In secondary education less than 3 percent of the girls in the relevant age group were enrolled, as compared with 15 percent of the boys.

During the past three decades the situation has improved significantly. Table 3 shows that while there are now 10 percent more boys enrolled in primary and secondary education as compared with the early half of the Fifties, enrollment for girls has increased by three times, at the primary level of education, and by 3.6 times at the secondary level. However, female enrollment rate at the primary level is still only half as much as that of males, while at the secondary level almost 90 percent of the females in the relevant age group are not enrolled at all.

Table 3 shows that the male-female differentials in enrollment rates are largest in the rural areas and there are also large differences in enrollment rates of urban and rural females. At the secondary level of education the urban rural differentials in enrollment rates, particularly for females, are the largest. In the rural areas of Sind, NWFP and Baluchistan less than 1 percent of the girls in the relevant age group are enrolled, while in Punjab only 3.2 percent of the females in the relevant age

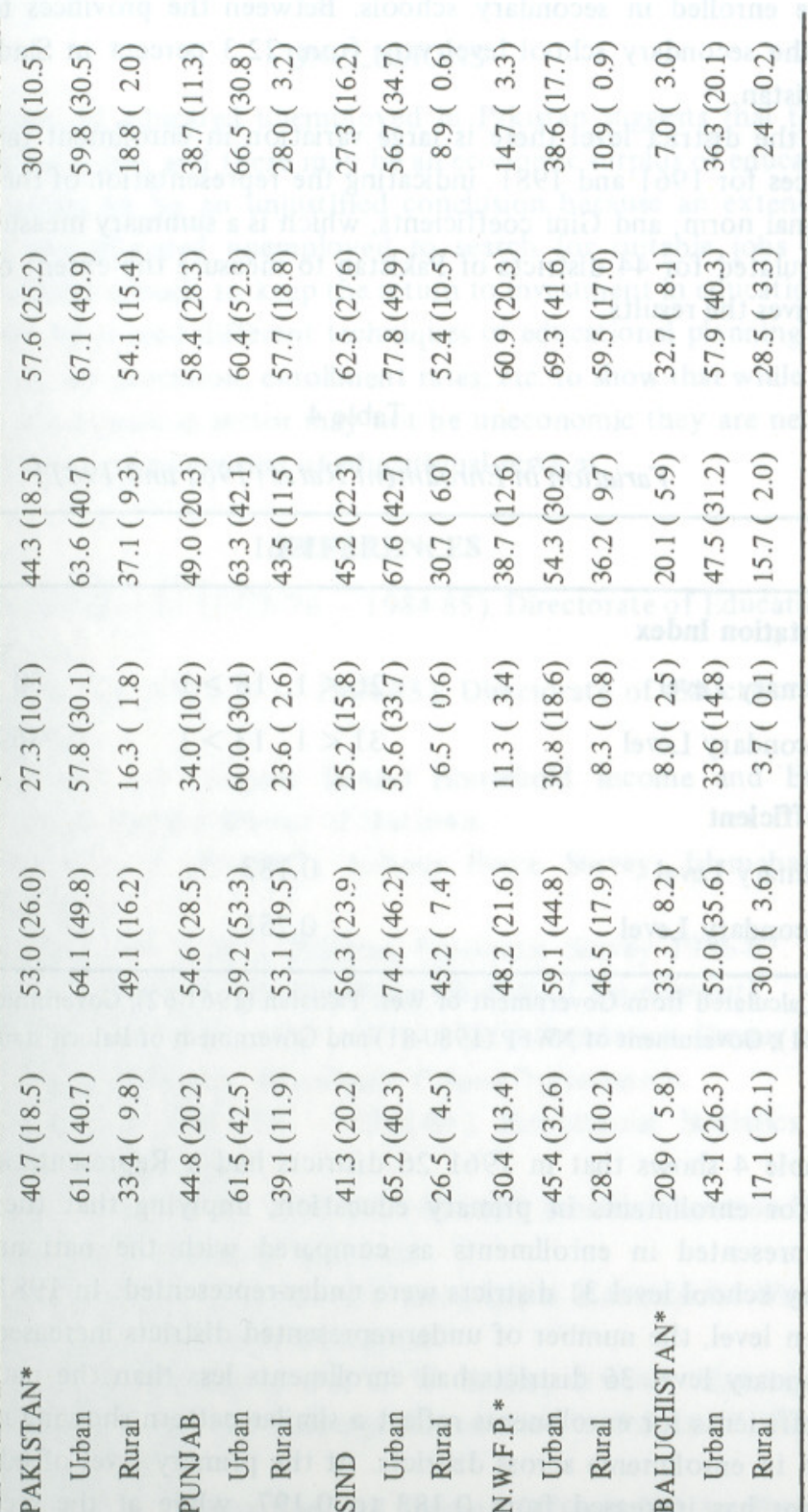


group are enrolled in secondary schools. Between the provinces total enrollment rates at the secondary school level vary from 22.3 percent in Sind to 5.9 percent in Baluchistan.

At the district level there is large variation in enrollment rates. Representation Indices for 1961 and 1981, indicating the representation of the district vis- $\dot{a}$-vis the national norm, and Gini coefficients, which is a summary measure of inequality, were calculated for 44 districts of Pakistan to measure the extent of this variation. Table 4 gives the results.

Table 4

Variation in Enrollment Rates (1961 and 1981)

\begin{tabular}{ccc}
\hline & 1961 & 1981 \\
\hline $\begin{array}{c}\text { Representation Index } \\
\text { Primary Level } \\
\text { Secondary Level }\end{array}$ & $26<1,18>1$ & $30<1,14>1$ \\
Gini Coefficient & $31<1,13>1$ & $36<1,8>1$ \\
Primary Level & & \\
Secondary Level & 0.183 & 0.197 \\
\hline
\end{tabular}

Source: Calculated from Government of West Pakistan (1961-62); Government of Sindh (198081); Government of NWFP (1980-81) and Government of Balochistan (1980-81).

Table 4 shows that in 196126 districts had a Representation Index of less than 1 for enrollments in primary education, implying that these districts were under-represented in enrollments as compared with the national norm. At the secondary school level 31 districts were under-represented. In 1981, at the primary education level, the number of under-represented districts increased to 30 , while at the secondary level 36 districts had enrollments less than the national norm. The Gini coefficients for enrollments reflect a similar pattern showing an increase in the variation in enrollments across districts. At the primary level of education the Gini coefficient has increased from 0.183 to 0.197 , while at the secondary level the increase has been from 0.251 to 0.272 . These figures show that during the period 1961 to 1981, despite a significant increase in enrollments, both at the primary and secondary levels, there has been an increase in the inequality in the distribution of schooling across various districts. Further, at the higher level of education there is greater variation in the availability of schooling and the inequality has worsened over time.

\section{CONCLUSIONS}

The presence of educated unemployed in Pakistan suggests that the productivity of education is low and there may be an economic surplus of education in the country. This seems to be an unjustified conclusion because an extended family system enables the educated unemployed to search for suitable jobs for a time period which is short enough to keep the return to investment in education positive. In this paper we have used different techniques of educational planning: aggregate social expenditure on education, enrollment rates, etc. to show that while additional investments in the education sector may not be uneconomic they are necessary for removing disparities in the provision of educational services.

\section{REFERENCES}

Balochistan, Government of (1975-76 - 1984-85). Directorate of Education Quetta. Unpublished data

NWFP, Government of (1975-76 - 1984-85). Directorate of Education Peshawar. Unpublished data.

Pakistan, Government of (Various Issues) Household Income and Expenditure Survey. Islamabad: Federal Bureau of Statistics.

Pakistan, Government of (1986-87). Labour Force Survey. Islamabad: Federal Bureau of Statistics.

Pakistan, Government of (1987). Pakistan Economic Survey 1986-87. Islamabad: Finance Division, Economic Advisers Wing. (Statistical Supplement)

Pakistan, Government of (1951, 1961, 1972, 1981). Population Census of Pakistan. Islamabad: Statistics Division, Population Census Organization.

Punjab, Government of (1975-76 - 1984-85). Educational Statistics in Punjab Lahore: Bureau of Education.

Sindh, Government of (1979-80, 1983-84, 1984-85). School Education Statistics in Sindh. Karachi: Sindh Bureau of Statistics.

West Pakistan, Government of (1961-62). Educational Statistics for West Pakistan. Lahore: West Pakistan Bureau of Education.

Guisinger, S. E., J. W. Henderson and G. W. Sculley (1984). "Earnings Rates of Return to Education and the Earnings Distribution in Pakistan". Economics of Education Review. Vol. 3

Hamdani, K. A. (1977). "Education and Income Differential: An Estimation for Rawalpindi City". Pakistan Development Review. Vol. XVI.

Haque, N. UI. (1977). An Economic Analysis of Personal Earnings in Rawalpindi city". Pakistan Development Review. Vol. XVI. pp. 353-382.

Khan, S. R., and M. Irfan (1985). "Rates of Return to Education and the Deter- 
minants of Earnings in Pakistan". Pakistan Development Review. Vol. XXIV, Nos. 3 \& 4 .

Khan, S. R., and S. Z. Ali (1986). "Some Findings about the Unemployed Highly Educated Persons in Pakistan". Pakistan Development Review. Vol. XXV, No. 4. pp. $731-737$.

\section{Comments on Education Sector"}

"Investment and Inequality in Pakistan's

The authors of the study have made a concerted effort to highlight inequalities in the distribution of education services across regions and gender. In the process they have presented a case for raising the expenditures on education which is a laudable objective. However, I feel that some observations are necessary so that issues raised in the paper can be clarified.

I will begin by saying that I feel slightly uncomfortable when I try to establish a link between the title of the paper, the introductory section and the concluding remarks. This may be due to the fact that the purpose of the study has not been clearly stated. If the objective of the paper is to make a case for getting more allocations for education specifically for primary and secondary levels, as the focus of the presentation reveals, then it has succeeded in getting across its message. But this does not help us in the existing situation. We are all aware that our educational base is poor not only because of persistent and serious under-funding but also because of inappropriate sub-sectoral allocations. To remedy the latter situation the investment bias in favour of higher education has been reversed recently by reallocating resources to primary and secondary education, but unfortunately implementation has not been up to the expectations of the planners. Thus, in my opinion, it would have been more useful had an attempt been made to first assess the performance of education, at least at the primary level, in terms of utilizing the allocated resources. According to one study by the Ministry of Education, Government of Pakistan upto 1980 the average utilization rate, especially at the primary level, has ranged between 30 and 40 percent. The study further reveals that the normal feature of the financial performance in these years has been to divert the unutilized allocations meant for primary education to higher education.

The section on enrolment is relatively well treated. Various quantitative techniques have been used to prove gender and region-wise inequalities in the distribution of education services. The authors conclude by saying that more allocations for the education sector are necessary for removing these inequalities. However, most of us are aware that in rural areas low enrolment, high drop-out and repeater rates are caused by an unattractive school environment, long travel distances to reach schools, high opportunity costs and an unusually low demand for education. In such a situation, more allocations by themselves are not sufficient. Hence, an 
effective strategy to reduce the rural-urban imbalance needs to be devised.

In the case of female education, especially in the rural areas, a pathetically low enrolment ratio requires serious attention from the policy-makers. The introduction of special basic female education programmes and motivational campaigns through the mass media, especially through television, is necessary to make female education acceptable to parents living in a conservative rural setting. Only then will female literacy be promoted. Simply demanding more allocations for the education sector can be justified in view of the low priority accorded to it in the past, but without formulating workable strat egies the desired results will not be achieved.

The authors have discussed the gravity of educated unemployment but have dismissed it on the grounds that "an extended family system enables the educated unemployed to search for suitable jobs for a time period which is short enough to keep the return to investment in education positive." The search time i.e. "short enough" needs to be defined. In this context, it would have been useful, if the findings of the studies carried out by the Federal Bureau of Statistics regarding Unemployment of Doctors (1984-85), Engineers (1981-83), Statistics, Economics and Commerce graduates (1981-83) had been used.

My last observation relates to Table 3 . The authors while describing the variation in enrollment rates have stated that 26 districts had a representation index of less than 1 for enrollment in primary education. It would have been very useful if these districts had been listed enabling the decision-makers at the national level to rectify the situation by way of planned development. Moreover, the national norm needs to be specified.

\section{Shamim A. Sahibzada}

Pakistan Institute of

Development Economics,

Islamabad 